\title{
Development of The Use of Reclaimed Asphalt Pavement and Plastic Waste in Hot Mix Asphalt for Road Maintenance
}

\author{
Ferdinan Nikson Liem ${ }^{1}$, Obed Oktafianus Nego Nenobais ${ }^{1}$, Melchior Bria ${ }^{1}$, Abia \\ Erasmus Mata ${ }^{1}$ \\ \{ferdynikson@gmail.com, obednenobais@gmail.com, melchibria@yahoo.co.id, \\ amustakppjj85@gmail.com\} \\ Kupang State Polytechnic, Indonesia ${ }^{1}$
}

\begin{abstract}
The technology of asphalt pavement recycling in road maintenance works has developed quite rapidly. Meanwhile, the use of plastic in hot asphalt mixtures has also developed. For this reason, the mix of RAP with LDPE plastics was carried out. The study was designed using a factorial experiment with a Completely Randomized Design (CRD) consisting of two factors and three levels. The first factor is the concentration of plastic levels of 3 levels, namely: $\mathrm{a} 1=10 \% ; \mathrm{a} 2=15 \%$ and $\mathrm{a} 3=25 \%$. The second factor $(\mathrm{B})$ is RAP with 3 levels of treatment, namely: $\mathrm{b} 1=0 \%$ new asphalt (pure RAP); b2 $=$ RAP + $2 \%$ new asphalt; $\mathrm{b} 3=\mathrm{RAP}+4 \%$ new asphalt. The results showed that the stability value increased sharply but on the one hand also increased the cavity in the mixture exceeds the required limits so further research is needed to find the right mixture composition.
\end{abstract}

Keywords: Maintenance, Reclaimed, Asphalt, Pavement, Plastics

\section{Introduction}

Road construction by the Government is intended to increase accessibility between regions. Until 2017 it was recorded that the length of roads in Indonesia was 539,415 km, with national roads $47,017 \mathrm{~km}$, provincial roads $55,416 \mathrm{~km}$ and city roads $436,912 \mathrm{~km}$ [1]. Whereas relating to conditions, national roads are in a steady state of $55.85 \%$, while $33.53 \%$ are damaged $10.62 \%$; the condition of the provincial road steady condition $69.82 \%$, not stable (damaged) $30.18 \%$; while the city road sections are steady conditions $56.93 \%$, conditions are not stable $43.07 \%$. Specifically in NTT, out of a total length of $2,958 \mathrm{~km}$, only $45.13 \%$ was steady, while $54.87 \%$ was not stable [2]. Therefore, every year the central and regional governments allocate funds for road maintenance. However, in Indonesia the handling of road damage is generally carried out in the same way on all road sections in the form of overlay [3]. As a result, it is often found that the road surface is getting thicker, causing changes in the surrounding environment and tends to be wasteful both in terms of cost and natural material [4].

To overcome this, the use of old reclaimed asphalt pavement (RAP) as an added or main ingredient in asphalt mixtures is the right solution. The reason is that the use of RAP maximizes economic benefits, reduces costs, can be implemented, has a short implementation time, and impacts on environmental preservation by reducing emissions and transitioning from nonrenewable energy to renewable energy [5] [6]. In the conventional method requires materials from nature to produce asphalt as a binder of crude oil and aggregate drying to produce asphalt mixtures in the hot mix plant (HMP) [7]. 
Meanwhile, the use of plastic in road pavement has been developed. Several studies have shown that plastic waste can be used as a material substitute for hot asphalt mixtures with concentrations up to $50 \%$ in the mixture that still meets the specifications of [8[ [9]. Previous research had been conducted where the material was Recycled Concrete Aggregate (RCA) from concrete cube laboratory test wastes and the results showed an increase in the Marshall Test value [10]. In this study, the specific specifications examined were the use of RAP material from existing road pavement (which is different in nature from the concrete asphalt test waste from the laboratory) and LDPE type plastic waste to be tested based on Bina Marga 2010 Edition revision 3. The measured parameters are value of stability and flow.

Basically the pavement layer consists of a lower foundation layer, an upper foundation layer, and a surface layer and there are differences between the types of flexible pavement and rigid pavement [11]. Flexible pavement is characterized by a surface layer in the form of asphalt on the base layer or foundation, can consist of one or more layers of asphalt or Hot Mix Asphalt (HMA), and has flexural strength so that it undergoes deformation while rigid pavement is characterized by high rigidity, in the form of concrete slabs and has a high elastic modulus on its surface. [12]. In this paper, we will discuss the effect of adding plastic and asphalt content on the stability value and VMA (Void In The Mineral Aggregate).

The use of asphalt from the process of refining petroleum for pavement is very widespread in Indonesia, potentially producing RAP material, ie used asphalt pavement from a mixture of crushed HMA then recycled with or without pure material and can be reused one of them for road maintenance [13]. This maintenance work is an activity to maintain the ability of road services through routine and periodic maintenance [14]

Basically, RAP derived from materials used in the surface layer is the result of the process of mixing various aggregates with asphalt binder. Some of the most commonly used types in Indonesia for surface coatings on road pavement [15] are hot mix asphalt, cold mixed asphalt and Macadam Penetration smears. Especially for hot asphalt mixture, in Indonesia uses several types of hot asphalt mixture campuran[14], namely: AC (Asphalt Concrete), HRS (Hot Rolled Sheets) and Sand Sheet.

The characteristics of the asphalt mixture that must be fulfilled to be used as pavement [12][13] are stability, resistance to fatigue and cracking; durability; resistance to stripping; workability and skid.

While plastic is a material that can be divided into two parts based on its nature, namely thermoplastic and thermosetting. Various types of plastics that can be found on the market are Polyethylene Terephthalate (PET), Polypropylene (PP), Polyvinyl Chloride (PVC), Polystyrene (PS), Low-Density Polyethylene (LDPE) and High-Density Polyethylene [15]. Because of its thermoplastic nature, plastics can change shape when heated and can be changed in shape, then freeze if cooled. Plastics are also materials that contain polymer compounds where polymers are often used in asphalt mixtures so that plastics can be used as additives in asphalt mixtures [13].

Ravindra [14], found that RCA (Recycled Concrete Asphalt) can be used up to $100 \%$ in a hydraulically bound mixture, without reducing its unlimited compressive strength to withstand heavy traffic loads. Modulus of stiffness, rutting resistance and fatigue resistance of bitumen mixtures containing up to $30 \%$ RCA were found to be acceptable. The use of RCA tends to reduce the resistance of asphalt mixtures to moisture damage, although this can be increased due to the use of anti-stripping agents.

Arshad [14] argues that RAP has the potential to be reused in controlled conditions and if used will bring significant benefits. The identification results show that the addition of RAP 
from $50 \%-75 \%$ can increase the strain up to $2500 \%$ when compared to originally mixing without RAP. However, the presence of RAP can increase sensitivity to pressure when compared to asphalt mixes without RAP.

Mousa \& Mousa [20], found that RAP can also be used in compacted subbase and subgrade layers. The use of RAP in the amount of $10-90 \%$, can increase the value of California Bearing Ratio (CBR) by 50-60\%. In the combination of 50\% RAP and 50\% fine aggregate it is very effective to be applied to the subgrade layer compared to the subgrade. The use of RAP with the composition as above can also save up to $70 \%$ of the budget compared to conventional sub-bases.

Several other studies that support the use of RAP also say that the use of RAP is very economical because it reduces the use of original (new) material and has an impact on improving the characteristics of asphalt mixtures [15][16][17].

\section{Method}

This research was in the form of an experiment at the Kupang State Polytechnic Material Testing Laboratory and selected roads based on a maintenance history of at least 3 years ago, Average Daily Traffic $2000 \mathrm{smp}$. The preliminary survey of the roads included in the category is the Bundaran PU and WJ Lalamentik street.

RAP material is taken randomly on both roads, using Core Drill available at the PNK Material Testing Laboratory. Plastic waste is the type of LDPE. It is strong, flexible, waterproof, the surface is not clear and soft at a temperature of $70^{\circ} \mathrm{C}$. The mixture process (mixdesign) is carried out by means of a dry process ie plastic waste is used as an aggregate modification material.

This research uses factorial experimental design in the form of a completely randomized design (CRD) of 2 factors and each factor consists of 3 levels. A factor is the concentration of plastic levels as much as 3 levels, namely: $\mathrm{a} 1=10 \%$; $\mathrm{a} 2=15 \%$ and $\mathrm{a} 3=25 \%$. Factor B is RAP with 3 levels of treatment, namely: $\mathrm{b} 1=0 \%$ new asphalt; $\mathrm{b} 2=\mathrm{RAP}+2 \%$ new asphalt (pen $60 / 70)$; b3 $=$ RAP $+4 \%$ new asphalt. The specimens were 9 combinations and were repeated 4 times so that a total of 36 units.

\section{Result and Discussion}

RAP re-mixing experiment with plastic waste is first examined the characteristics of RAP and plastic waste. Examination of the characteristics of the RAP is important in order to determine the initial properties of RAP and plastic waste that meet specifications. Table 1 shows the characteristics of plastics used in the form of Polytehylene (PE) plastic pellets with specifications meeting the Low Density Polyethylene (LDPE) type. This LDPE has a density between $0.91 \mathrm{~g} / \mathrm{mL}$, half of which is crystalline around $50-60 \%$ and has a melting point of $115^{\circ} \mathrm{C}$.

Table 1 Plastic Waste Requirements

\begin{tabular}{l|c|c}
\hline \multicolumn{1}{c|}{ Characteristic } & The requirements & Test Result \\
\hline Item escaped sieve 3/8 inci $(9,5 \mathrm{~mm}) \%$ & 100 & 100 \\
\hline Item escaped sieveNo. $4(4,75 \mathrm{~mm}) \%$ & 90 & 90 \\
\hline Thickness $(\mathrm{mm})$ & Max 0,07 & 0,05 \\
\hline Water Content $(\%)$ & Max 5\% & 4 \\
\hline Melting Point $\left({ }^{\circ} \mathrm{C}\right)$ & $100-120$ & 115 \\
\hline
\end{tabular}




\subsection{Marshall Test}

As explained in Table 1, for Marshall examination several parameters are used to evaluate compliance with applicable standards. The parameters generated directly using Marshall tools are actually only stability and flow values, while other values such as VIM, VMA \& VFA and Marshall Quotient are obtained from weighing test and calculation (pore volume / cavity or volumetric solid hot asphalt mixture).

Table 2 shows that the stability value tends to increase with the addition of asphalt and plastic levels in the mixture. From the linear regression equation for each variation of plastic content in the mixture, it can be seen the trend of increasing stability (Figure $1 \mathrm{a}-\mathrm{c}$ ).

Tabel 2. Value of Stability, VMA and Flow Value

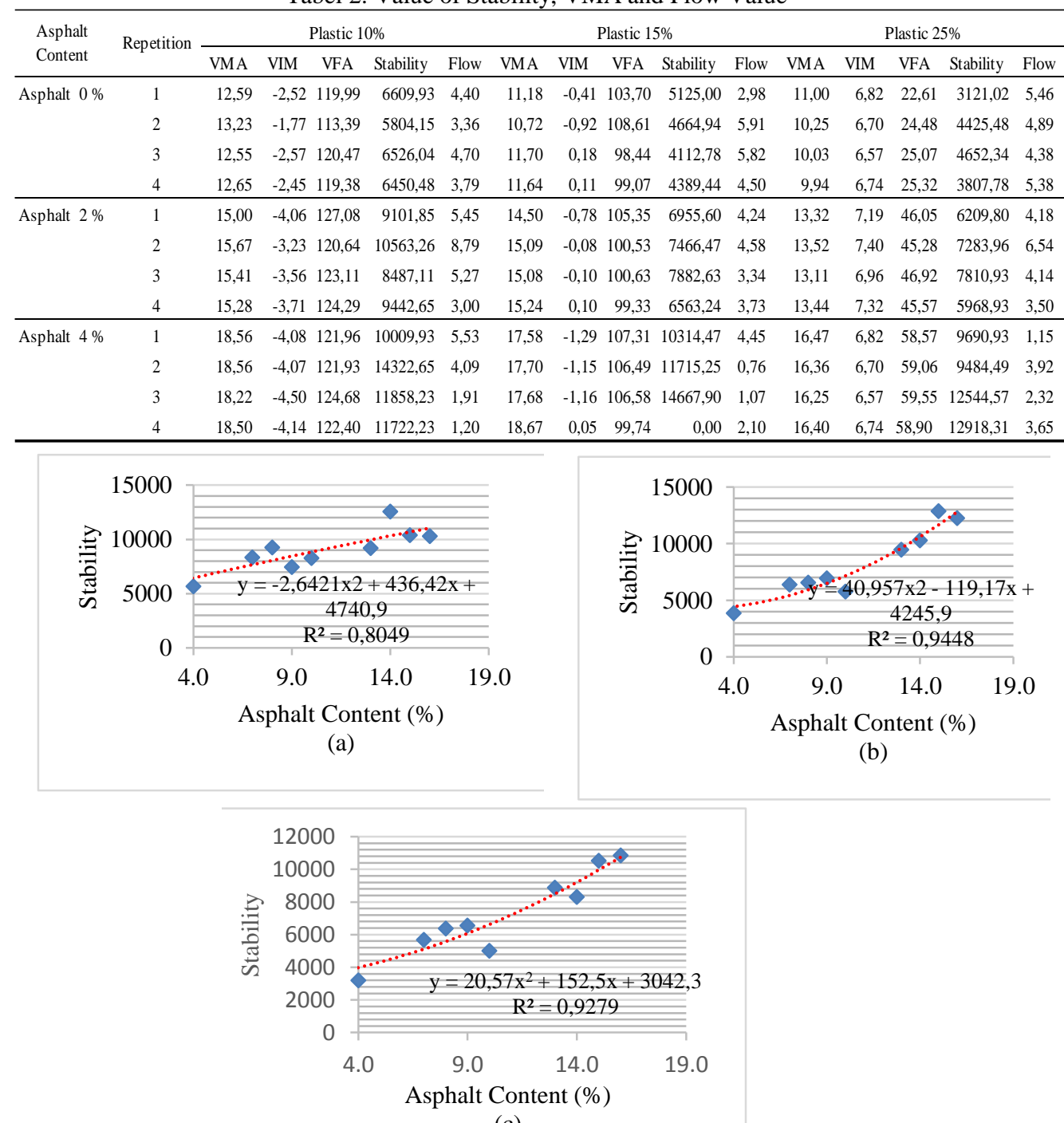

(c)

Figure 1. The relationship between asphalt content and stability (a) with $10 \%$ plastic (b) with $15 \%$ plastic and (c) $25 \%$ plastic 
The Figure shows that the addition of asphalt and plastic content in the mixture causes a very high stability value. For example if without adding asphalt content to the RAP with a plastic composition of $10 \%$ in the RAP mixture, the stability value is $4740.09>800$ (minimum).

However, the addition of plastic and asphalt content tends to increase flow because it exceeds the maximum limit of $6 \mathrm{~mm}$ for the base layer and $4 \mathrm{~mm}$ for surface and binder courses as shown in Figure 2.

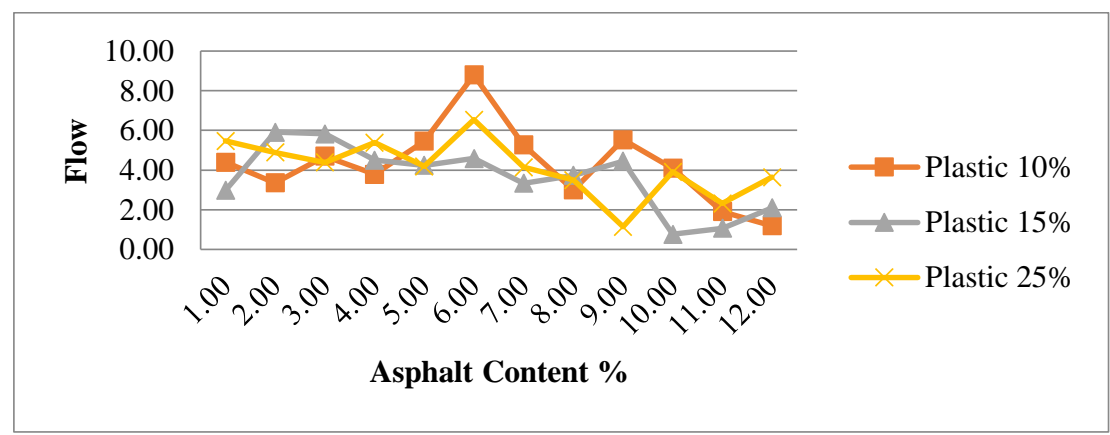

Figure 2. The Relationship between asphalt content and flow

Addition, based on the results of the analysis, VMA values were obtained from various variations of asphalt mixtures and plastic waste. The results show that the required minimum VMA value was not achieved in some mix variations and repetitions in the test. This is evident from Figure $3(\mathrm{a}-\mathrm{c})$, where the curve to the left cuts the boundary line at least $15 \%$ as a boundary condition on the surface course.

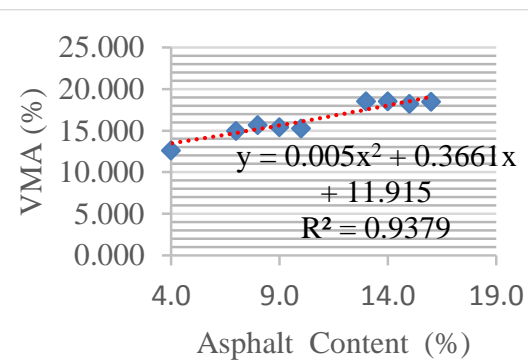

(a)

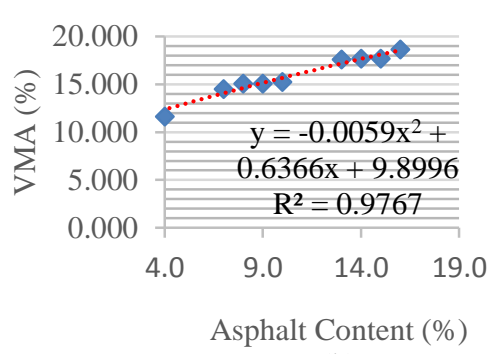

(b)

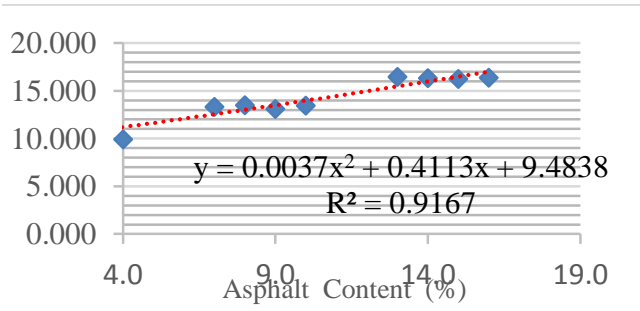

(c)

Figure 3. The relationship between asphalt levels and stability (a) with $10 \%$ plastic (b) with $15 \%$ plastic and (c) $25 \%$ plastic

From Figure 3 above it is clearly seen that all regression equations that can be formed show that in mixed conditions without the addition of asphalt content, the VMA value is below $15 \%$ and 
each addition of asphalt levels causes an increase in VMA values. The existence of a VMA value that crosses this boundary line will directly cause the VIM value not to be met.

\subsection{Hypothesis Analysis}

To determine the distribution of data and see the effect of giving treatment to asphalt mixes, analysis of variance (ANOVA) was performed. Next there are three hypotheses related to the effect of adding asphalt and plastic levels:

The first hypothesis

Ho: The addition of asphalt and plastic content in the RAP mixture affects the stability value H1: The addition of asphalt and plastic content in the RAP mixture has no effect on the stability value

Table 3 Anova : VMA vs Asphalt Content \& Plastic

\begin{tabular}{cccccc}
\hline Total & DF & SS & MS & F & P \\
\hline Asphalt Content & 2 & 225,057 & 112,529 & 774,71 & 0,000 \\
Plastic & 2 & 29,152 & 14,576 & 100,35 & 0,000 \\
Error & 31 & 4,503 & 0,145 & & \\
Source & 35 & 258,712 & & & \\
& $\mathrm{~S}=0,3811$ & R-Sq $=98,26 \%$ & R-Sq(adj) $=98,03 \%$ & \\
\hline
\end{tabular}

From Table 3 it can be seen that asphalt and plastic have a value of $p=0,000<0.05$ so reject $\mathrm{H} 1$ which means the addition of plastic and asphalt content has a significant effect on the VMA value of asphalt mixture (RAP).

The second hypothesis

Ho: The addition of asphalt and plastic content in the RAP mixture affects the VMA value $\mathrm{H} 1$ : The addition of asphalt and plastic content in the RAP mixture has no effect on the VMA value

Table 4 Anova : Stability vs Asphalt Content and Plastic

\begin{tabular}{cccccc}
\hline Total & DF & SS & MS & F & P \\
\hline Asphalt Content & 2 & 294028488 & 147014244 & 92,36 & 0,000 \\
Plastic & 2 & 22141991 & 11070995 & 6,96 & 0,003 \\
Error & 31 & 49343116 & 1591713 & & \\
Source & 35 & 365513594 & & & \\
\hline $\mathrm{S}=1262 \quad \mathrm{R}-\mathrm{Sq}=86,50 \%$ & $\mathrm{R}-\mathrm{Sq}(\operatorname{adj})=84,76 \%$ & & & \\
\hline
\end{tabular}

From Table 3 it can be seen that both asphalt and plastic have a $p$ value of 0.05 , which means that the addition of asphalt and plastic to the RAP mixture has a significant effect on the stability value.

The third hypothesis

Ho: The addition of asphalt and plastic content in the RAP mixture affects the flow value H1: The addition of asphalt and plastic content to the RAP mixture has no effect on the flow value

Table 5 Anova : Flow vs Asphalt Content \& Plastic

\begin{tabular}{cccccc}
\hline Total & DF & SS & MS & F & P \\
\hline Asphalt Content & 2 & 32,1360 & 16,0680 & 7,75 & 0,002 \\
Plastic & 2 & 2,9053 & 1,4526 & 0,70 & 0,505 \\
Error & 27 & 55,9584 & 2,0725 & & \\
Source & 35 & 98,1378 & & & \\
\hline $\mathrm{S}=1,440 \quad \mathrm{R}-\mathrm{Sq}=42,98 \%$ & $\mathrm{R}-\mathrm{Sq}(\mathrm{adj})=26,08 \%$ & & \\
\hline
\end{tabular}


From Table 5 it can be seen that the addition of asphalt $p$ value $<0.05$ so it can be said to be significant reject $\mathrm{H} 1$, which means the addition of asphalt levels affects the flow value. Whereas on the addition of plastic, the value of $p>0.05$ so that the decline of Ho which means the provision of plastic content does not affect the change in flow value.

Table 6 Standard deviation

\begin{tabular}{c|c|c|c|c|c}
\hline Variable & $\mathrm{N}$ & Mean & StDev & SE Mean & $95 \%$ CI \\
\hline Stability & 36 & 8240 & 3232 & 539 & $(7147 ; 9334)$ \\
VMA & 36 & 14,530 & 2,719 & 0,453 & $(13,610 ; 15,449)$ \\
Flow & 36 & 4,013 & 1,674 & 0,279 & $(3,447 ; 4,580)$ \\
\hline
\end{tabular}

While from Table 6, it appears that the value of the SE Mean or standard deviation error is very small so that it can be said that the data are close to the actual conditions.

\subsection{Discussion}

From the above analysis, we can see that the addition of plastic to RAP asphalt shavings with or without the addition of asphalt content, has a significant effect on pavement performance. The gain can be seen in the increased value of the stability of the RAP for all variations of the experiment. However, on the other hand, the VMA value shows an inconsistent value, meaning that from the curve the relationship of VMA with asphalt content in all variations of the plastic percentage shows a VMA value that is below the standard. This will have an impact on the value of VIM will also be relatively small as well. Theoretically, the small VMA and VIM values will increase sensitivity to changes in asphalt content so that if the asphalt content goes to the left of the curve, the mixture will be too dry and the air cavity is too high. A mixture that is too dry and a large air cavity is one of the causes of cracking and disintegration whereas if the asphalt level is higher (to the right) it will cause melting and plastic deformation.

Related to the use of plastics, Aschuri [18], examined using small sized plastic waste that passed filter number 30 and held in filter number 40, which would replace (weight) a portion of mineral aggregate. All mixtures were prepared using $5.82 \%$ optimum asphalt content. The performance characteristics of asphalt concrete were examined using Marshall test, indirect tensile strength test (ITS), indirect tensile modulus stiffness test (ITSM), and Cantabro Loss (CL) test which is associated with strength, modulus of stiffness, and durability characteristics. In general, laboratory results show that concrete asphalt mixtures containing plastic waste have higher performance than conventional asphalt concrete mixes. In addition, the results mentioned above are also strengthened by the research of Htwe, [19], which conducted an experiment focusing on aspects of Stone Mastic Asphalt (SMA). The results show that the addition of plastic waste to the asphalt mixture with 10\% LDPE, 10\% PP, and 25\% PS and 2\% HDPE can provide satisfactory performance values and increased stability and decreased flow value. So they appear to produce longer sidewalks.

\subsection{Conclusion}

The use of plastic in asphalt mixes is not in doubt either in new asphalt mixes or in old pavement waste materials. However, the results of this study found that high stability was not followed by improved VMA, VIM and flow values. The results of this study also show the trend of VMA values and flow away and close to the standard values set. For this reason, further studies need to be carried out to find the optimum asphalt levels that have been added with plastic so that all test parameters can be in accordance with applicable standards. 


\section{Acknowledge}

Thank you to the Kupang State Polytechnic through the Institute for Research and Community Service for providing research funding and facilitating the implementation of this research.

\section{References}

[1] Center of Data and Information Technology, Buku Informasi Statistik, Ministry For Public Works and Human Settlements (2017)

[2] Bria M., Muda A.H., and Dumin L., Determination of the Value of the Conditions and Program of Maintenance of Roads, Jurnal Inersia Vol. VII No. 2, September (2015)

[3] Federal Highway Administration, Reclaimed Asphalt Pavement in Asphalt Mixtures: State of the Practice, US Department of Transportation, (2011)

[4] Lyubarskaya M.A., Merkusheva V.S., Osian P.A., Ilin A.A., Svintsov E.S., 2017, Integrated Approach to using Technology of Reclaimed Asphalt Pavement (RAP), Procedia Engineering Vol. 189, pp. 860 - 866 (2017)

[5] Pradyumna T.A., Mittal A., Jain P.K, Characterization of Reclaimed Asphalt Pavement (RAP) for Use in Bituminous Road Construction, Procedia - Social and Behavioral Sciences, Vol. 104, pp. 1149 - 1157 ( 2013)

[6] Tajudin, A. N., Suparma, L.B., Utilization of HDEP Plastic Waste as a Replacement Aggregate in Asphalt Concrete - Binder Course Mixes $(A C-B C)$, The 17th FSTPT International Symposium, Jember University (2014)

[7] Faishal, M. Y., Effect of Addition of Poly Propilene (PP) Plastic Waste to Hotmix Asphalt Concrete Against Marshall Parameters, Skripsi, Prodi S1 Pendidikan Teknik Bangunan, Fakultas Teknik, Universitas Negeri Malang (2014)

[8] Al-Humeidawi B.H., Utilization of Waste Plastic and Recycle Concrete Aggregate in Production of Hot Mix Asphalt, Al-Qadisiya Journal For Engineering Sciences, Vol. 7 No. 4, pp. 322 - 330 (2014)

[9] Direktorat Jenderal Bina Marga, 2013, Mannualof Pave,ent Desain Nomor 02/M.BM/ 2013, Ministry For Public Works and Human Settlements (2013)

[10] Mir A.H., 2015, Use of Plastic Waste in Pavement Construction: An Example of Creative Waste Management, IOSR Journal of Engineering (IOSRJEN) Vol. 05, Issue 02 , pp. 57-67 (2015)

[11] Vaza H., et al, Application of Full Scale Asphalt Waste Plastic Technology, Balitbang BBPJN VIII Surabaya, Ministry For Public Works and Human Settlements (2017)

[12] Ravindra K., OBE D., Brito J., Silva R.V., QunLye C., 2019, Use of Recycled Aggregates in Road Pavement Applications, Sustainable Construction Materials, Woodhead Publishing Series in Civil and Structural Engineering, pp. 451-494 (2019)

[13] Arshad M, Experimental evaluation of constitutive models for the estimation of resilient modulus values and an assessment of pressure sensitivity ofgranular blends containing reclaimed asphalt pavement materials, Construction and Building Materials Vol. 180, pp. 491-502 (2018)

[14] Mousa R., Mousa M., Viability Assessment of Using Reclaimed Asphalt Pavement Sand Blend in Road Construction: A Case Study in Egypt, The 96th Transportation Research Board Annual Meeting January 8-12, Washington, D.C. (2017)

[15] Izaksa R., et al., Hot Mix Asphalt RAP, Procedia Engineering, Vol 114, pp. 676 - 684 (2015)

[16] Hussaina A., Yanjuna Q., Effect of Reclaimed Asphalt Pavement on the Properties of Asphalt Binders, Procedia Engineering, Vol. 54, pp. 840 - 850 ( 2013 )

[17] Noferini L., Simone A., Sangiorgi C., Mazzotta F., Investigation on performances of asphalt mixtures made with Reclaimed Asphalt Pavement: Effects of interaction between virgin and RAP bitumen, International Journal of Pavement Research and Technology Vol. 10, pp. 322-332 (2017)

[18] Aschuri I., Yamin A., Widyasih Y.D., The Use of Waste Plastic as a Partial Substitution Aggregate in Asphalt Concrete Pavement, Jurnal Teknik Sipil-ITB, Vol. 23 No. 1, pp.1-6 (2016)

[19] Htwe A.A., et al. Recycled Waste Plastics Modified Asphalt Concrete in Flexible Pavement for Infrastructure, Proceedings of Researchfora 7th International Conference, Singapore, 2nd -3rd June, pp. 19-21 (2017) 